\title{
Coincidence and fixed point results for generalized weak contractions in the sense of Berinde on partial metric spaces
}

\author{
Wasfi Shatanawi ${ }^{1}$ and Mihai Postolache ${ }^{2 *}$
}

\section{"Correspondence:}

mihai@mathem.pub.ro

${ }^{2}$ Faculty of Applied Sciences,

University Politehnica of Bucharest,

313 Splaiul Independenţei,

Bucharest, 060042, Romania

Full list of author information is

available at the end of the article

\begin{abstract}
In this paper, we introduce the notion of a generalized $(\phi, L)$-weak contraction and we prove some common fixed point results for self-mappings $T$ and $S$ and some fixed point results for a single mapping $T$ by using a (c)-comparison function and a comparison function in the sense of Berinde in a partial metric space. Also, we introduce an example to support the useability of our results.
\end{abstract}

MSC: $47 \mathrm{H} 10 ; 54 \mathrm{H} 25$

Keywords: partial metric space; weak contraction; fixed point

\section{Introduction and preliminaries}

The contraction principle of Banach is one of the most important results in nonlinear analysis. After Banach established his existence and uniqueness result, many authors established important fixed point theorems in the literature. For the development of our research, in this article, the article by Matthews [1] is the background.

In 1994, in his elegant article [1], Matthews introduced the notion of a partial metric space and proved the contraction principle of Banach in this new framework. After then, many fixed point theorems in partial metric spaces have been given by several authors (for example, please see [2-24]).

Following Matthews [1], the notion of a partial metric space is given as follows.

Definition 1.1 [1] A partialmetric on a nonempty set $X$ is a function $p: X \times X \rightarrow \mathbb{R}^{+}$such that for all $x, y, z \in X$ :

$\left(\mathrm{p}_{1}\right) x=y \Longleftrightarrow p(x, x)=p(x, y)=p(y, y)$,

$\left(\mathrm{p}_{2}\right) p(x, x) \leq p(x, y)$,

$\left(\mathrm{p}_{3}\right) p(x, y)=p(y, x)$,

$\left(\mathrm{p}_{4}\right) \quad p(x, y) \leq p(x, z)+p(z, y)-p(z, z)$.

A partial metric space is a pair $(X, p)$ such that $X$ is a nonempty set and $p$ is a partial metric on $X$.

It is clear that each partial metric $p$ on $X$ generates a $T_{0}$ topology $\tau_{p}$ on $X$. The set $\left\{B_{p}(x, \varepsilon): x \in X, \varepsilon>0\right\}$, where $B_{p}(x, \varepsilon)=\{y \in X: p(x, y)<p(x, x)+\varepsilon\}$ for all $x \in X$ and $\varepsilon>0$, forms the base of $\tau_{p}$.

D 2013 Shatanawi and Postolache; licensee Springer. This is an Open Access article distributed under the terms of the Creative Commons Attribution License (http://creativecommons.org/licenses/by/2.0), which permits unrestricted use, distribution, and reproduction in any medium, provided the original work is properly cited. 
It is remarkable that if $p$ is a partial metric on $X$, then the functions

$$
p^{s}: X \times X \rightarrow \mathbb{R}^{+}, \quad p^{s}(x, y)=2 p(x, y)-p(x, x)-p(y, y)
$$

and

$$
p^{w}: X \times X \rightarrow \mathbb{R}^{+}, \quad p^{w}(x, y)=2 p(x, y)-\min \{p(x, x), p(y, y)\}
$$

are ordinary equivalent metrics on $X$.

Definition 1.2 [1] Let $(X, p)$ be a partial metric space. Then:

(1) A sequence $\left\{x_{n}\right\}$ in a partial metric space $(X, p)$ converges to a point $x \in X$ if and only if $p(x, x)=\lim _{n \rightarrow \infty} p\left(x, x_{n}\right)$.

(2) A sequence $\left\{x_{n}\right\}$ in a partial metric space $(X, p)$ is called a Cauchy sequence if there exists (and is finite) $\lim _{n, m \rightarrow \infty} p\left(x_{n}, x_{m}\right)$.

(3) A partial metric space $(X, p)$ is said to be complete if every Cauchy sequence $\left\{x_{n}\right\}$ in $X$ converges, with respect to $\tau_{p}$, to a point $x \in X$ such that $p(x, x)=\lim _{n, m \rightarrow \infty} p\left(x_{n}, x_{m}\right)$.

The following lemma is crucial in proving our main results.

Lemma 1.1 [1] Let $(X, p)$ be a partial metric space.

(1) $\left\{x_{n}\right\}$ is a Cauchy sequence in $(X, p)$ if and only if it is a Cauchy sequence in the metric $\operatorname{space}\left(X, p^{s}\right)$.

(2) A partial metric space $(X, p)$ is complete if and only if the metric space $\left(X, p^{s}\right)$ is complete. Furthermore, $\lim _{n \rightarrow \infty} p^{s}\left(x_{n}, x\right)=0$ if and only if

$$
p(x, x)=\lim _{n \rightarrow \infty} p\left(x_{n}, x\right)=\lim _{n, m \rightarrow \infty} p\left(x_{n}, x_{m}\right)
$$

The definition of a 0-complete partial metric space is given by Romaguera [19] as follows.

Definition 1.3 [19] A sequence $\left\{x_{n}\right\}$ in a partial metric space $(X, p)$ is called 0-Cauchy if $\lim _{n, m \rightarrow+\infty} p\left(x_{n}, x_{m}\right)=0$. We say that $(X, p)$ is 0 -complete if every 0 -Cauchy sequence in $X$ converges, with respect to $\tau_{p}$, to a point $x \in X$ such that $p(x, x)=0$.

We need the following useful lemma in the proof of our main result.

Lemma 1.2 [2] Assume that $x_{n} \rightarrow z$ as $n \rightarrow+\infty$ in a partial metric space $(X, p)$ such that $p(z, z)=0$. Then $\lim _{n \rightarrow+\infty} p\left(x_{n}, y\right)=p(z, y)$ for every $y \in X$.

In [25], Berinde introduced the nonlinear type weak contraction using a comparison function. A map $\phi:[0,+\infty) \rightarrow[0,+\infty)$ is called a comparison function if it satisfies:

(i) $\phi$ is monotone increasing,

(ii) $\lim _{n \rightarrow+\infty} \phi^{n}(t)=0$ for all $t \geq 0$.

If $\phi$ satisfies (i) and

(iii) $\sum_{n=0}^{\infty} \phi^{n}(t)$ converges for all $t \geq 0$,

then $\phi$ is said to be a $(c)$-comparison function. 
It is an easy matter to see that if $\phi$ is a comparison function or a (c)-comparison function, then $\phi(t)<t$ for all $t>0$ and $\phi(0)=0$.

Berinde $[26,27]$ initiated the concept of weak contraction mappings, the concept of almost contraction mappings and the concepts of $(\phi, L)$-weak contractions. Berinde [25$32]$ studied many interesting fixed point theorems for weak contraction mappings, almost contraction mappings and $(\phi, L)$-weak contraction mappings in metric spaces. We have to recall the following definition.

Definition 1.4 [25] A single-valued mapping $f: X \rightarrow X$ is called a Cirić strong almost contraction if there exist a constant $\alpha \in[0,1)$ and some $L \geq 0$ such that

$$
d(f x, f y) \leq \alpha \max \left\{d(x, y), d(x, f x), d(y, f y), \frac{d(x, f y)+d(y, f x)}{2}\right\}+L d(y, f x)
$$

for all $x, y \in X$.

For some theorems of almost contractive mappings in the sense of Berinde on metric spaces, we refer the reader to [33-42].

Very recently, Ishak Altun and Özlem Acar initiated the notions of a $(\delta, L)$-weak contraction and a $(\phi, L)$-weak contraction in partial metric spaces as follows.

Definition 1.5 [43] Let $(X, p)$ be a partial metric space. A map $T$ is called a $(\delta, L)$-weak contraction if there exist a $\delta \in[0,1)$ and some $L \geq 0$ such that

$$
p(T x, T y) \leq \delta p(x, y)+L p^{w}(y, T x) .
$$

Because of the symmetry of the distance, the $(\delta, L)$-weak contraction condition implicitly includes the following dual one:

$$
p(T x, T y) \leq \delta p(x, y)+L p^{w}(x, T y) .
$$

Thus by (1.3) and (1.4), the $(\delta, L)$-weak contraction condition can be replaced by the following condition:

$$
p(T x, T y) \leq \delta p(x, y)+L \min \left\{p^{w}(y, T x), p^{w}(x, T y)\right\} .
$$

Definition 1.6 [43] Let $(X, p)$ be a partial metric space. A map $T$ is called $(\phi, L)$-weak contraction if there exist a comparison function $\phi$ and some $L \geq 0$ such that

$$
p(T x, T y) \leq \phi(p(x, y))+L p^{w}(y, T x) .
$$

As above, because of the symmetry of the distance, the $(\phi, L)$-weak contraction condition implicitly includes the following dual one:

$$
p(T x, T y) \leq \phi(p(x, y))+L p^{w}(x, T y) .
$$


Thus, by (1.6) and (1.7), the $(\phi, L)$-weak contraction condition can be replaced by the following condition:

$$
p(T x, T y) \leq \delta \phi(p(x, y))+L \min \left\{p^{w}(y, T x), p^{w}(x, T y)\right\} .
$$

Altun and Acar [43] proved the following interesting theorems.

Theorem 1.1 [43] Let $(X, p)$ be a 0-complete partial metric space and $T: X \rightarrow X$ be a $(\phi, L)$-weak contraction mapping with a (c)-comparison function, then $T$ has a fixed point.

Theorem 1.2 [43] Let $(X, p)$ be a 0-complete partial metric space and $T: X \rightarrow X$ be a $(\phi, L)$-weak contraction mapping. Suppose $T$ also satisfies the following condition: There exist a comparison function $\phi_{1}$ and some $L_{1} \geq 0$ such that

$$
p(T x, T y) \leq \phi_{1}(p(x, y))+L_{1} p^{w}(x, T x)
$$

for all $x, y \in X$. Then $T$ has a unique fixed point.

In this paper, we introduce the notion of a generalized $(\delta, L)$-weak contraction mapping and a generalized $(\phi, L)$-weak contraction mapping in partial metric spaces. Then after, we prove some fixed point results for two mappings $S$ and $T$ and some fixed point results for a single mapping $T$. Our results generalize Theorems 1.1 and 1.2.

\section{The main result}

We start our work by introducing the following two concepts.

Definition 2.1 Let $(X, p)$ be a partial metric space and $T, S: X \rightarrow X$ be two mappings. The pair $(T, S)$ is called a generalized $(\delta, L)$-weak contraction if there exist $\delta \in[0,1)$ and some $L \geq 0$ such that

$$
\begin{aligned}
p(T x, S y) \leq & \delta \max \left\{p(x, y), p(x, T x), p(y, T y), \frac{1}{2}(p(x, S y)+p(T x, x))\right\} \\
& +L \min \left\{p^{w}(x, S y), p^{w}(T x, y)\right\}
\end{aligned}
$$

for all $x, y \in X$.

Definition 2.2 Let $(X, p)$ be a partial metric space and $T, S: X \rightarrow X$ be two mappings. Then the pair $(T, S)$ is called a generalized $(\phi, L)$-weak contraction if there exist a control function $\phi$ and some $L \geq 0$ such that

$$
\begin{aligned}
p(T x, S y) \leq & \phi\left(\max \left\{p(x, y), p(x, T x), p(y, S y), \frac{1}{2}(p(T x, y)+p(x, S y))\right\}\right) \\
& +L \min \left\{p^{w}(x, S y), p^{w}(T x, y)\right\}
\end{aligned}
$$

for all $x, y \in X$.

Now, we give and prove our first result. 
Theorem 2.1 Let $(X, p)$ be a 0 -complete partial metric space and $T, S: X \rightarrow X$ be two mappings such that the pair $(T, S)$ is a generalized $(\phi, L)$-weak contraction. If $\phi$ is a $(c)$ comparison function, then $T$ and $S$ have a common fixed point.

Proof Choose $x_{0} \in X$. Put $x_{1}=T x_{0}$. Again, put $x_{2}=S x_{1}$. Continuing this process, we construct a sequence $\left(x_{n}\right)$ in $X$ such that $x_{2 n+1}=T x_{2 n}$ and $x_{2 n+2}=S x_{2 n+1}$. Suppose $p\left(x_{n}, x_{n+1}\right)=0$ for some $n \in \mathbb{N}$. Without loss of generality, we assume $n=2 k$ for some $k \in \mathbb{N}$. Thus $p\left(x_{2 k}, x_{2 k+1}\right)=0$. Now, by $(2.2)$, we have

$$
\begin{aligned}
& p\left(x_{2 k+1}, x_{2 k+2}\right) \\
&= p\left(T x_{2 k}, S x_{2 k+1}\right) \\
& \leq \phi\left(\operatorname { m a x } \left\{p\left(x_{2 k}, x_{2 k+1}\right), p\left(x_{2 k}, T x_{2 k}\right), p\left(x_{2 k+1}, S x_{2 k+1}\right),\right.\right. \\
&\left.\left.\frac{1}{2}\left(p\left(x_{2 k}, S x_{2 k+1}\right)+p\left(T x_{2 k}, x_{2 k+1}\right)\right)\right\}\right) \\
&+L \min \left\{p^{w}\left(T x_{2 k}, x_{2 k+1}\right)+p^{w}\left(x_{2 k}, S x_{2 k+1}\right)\right\} \\
&= \phi\left(\max \left\{p\left(x_{2 k+1}, x_{2 k+2}\right), \frac{1}{2}\left(p\left(x_{2 k}, x_{2 k+2}\right)+p\left(x_{2 k+1}, x_{2 k+1}\right)\right)\right\}\right) \\
&+L \min \left\{p^{w}\left(x_{2 k+1}, x_{2 k+1}\right)+p^{w}\left(x_{2 k}, x_{2 k+2}\right)\right\} \\
& \leq \phi\left(\max \left\{p\left(x_{2 k+1}, x_{2 k+2}\right), \frac{1}{2}\left(p\left(x_{2 k}, x_{2 k+1}\right)+p\left(x_{2 k+1}, x_{2 k+2}\right)\right)\right\}\right) \\
& \leq \phi\left(p\left(x_{2 k+1}, x_{2 k+2}\right)\right) .
\end{aligned}
$$

Since $\phi(t)<t$ for all $t>0$, we conclude that $p\left(x_{2 k+1}, x_{2 k+2}\right)=0$. By $\left(\mathrm{p}_{1}\right)$ and $\left(\mathrm{p}_{2}\right)$ of the definition of partial metric spaces, we have $x_{2 k+1}=x_{2 k+2}$. So, $x_{2 k}=x_{2 k+1}=x_{2 k+2}$. Therefore $x_{2 k}=T x_{2 k}=S x_{2 k}$ and hence $x_{k}$ is a fixed point of $T$ and $S$. Thus, we may assume that $p\left(x_{n}, x_{n+1}\right) \neq 0$ for all $n \in \mathbb{N}$. Given $n \in \mathbb{N}$. If $n$ is even, then $n=2 t$ for some $t \in \mathbb{N}$. By (2.2), we have

$$
\begin{aligned}
& p\left(x_{2 t}, x_{2 t+1}\right) \\
&= p\left(x_{2 t+1}, x_{2 t}\right) \\
&= p\left(T x_{2 t}, S x_{2 t-1}\right) \\
& \leq \phi\left(\operatorname { m a x } \left\{p\left(x_{2 t}, x_{2 t-1}\right), p\left(x_{2 t}, T x_{2 t}\right), p\left(x_{2 t-1}, S x_{2 t-1}\right),\right.\right. \\
&\left.\left.\frac{1}{2}\left(p\left(x_{2 t}, S x_{2 t-1}\right)+p\left(T x_{2 t}, x_{2 t-1}\right)\right)\right\}\right) \\
&+L \min \left\{p^{w}\left(x_{2 t}, S x_{2 t-1}\right), p^{w}\left(T x_{2 t}, x_{2 t-1}\right)\right\} \\
&=\left(\max \left\{p\left(x_{2 t}, x_{2 t-1}\right), p\left(x_{2 t}, x_{2 t+1}\right), \frac{1}{2}\left(p\left(x_{2 t}, x_{2 t}\right)+p\left(x_{2 t+1}, x_{2 t-1}\right)\right)\right\}\right) \\
&+L \min \left\{p^{w}\left(x_{2 t}, x_{2 t}\right), p^{w}\left(x_{2 t+1}, x_{2 t-1}\right)\right\} .
\end{aligned}
$$


Using $\left(\mathrm{p}_{4}\right)$ of the definition of partial metric spaces and the definition of $p^{w}$, we arrive at

$$
\begin{aligned}
p\left(x_{2 t}, x_{2 t+1}\right) & \leq \phi\left(\max \left\{p\left(x_{2 t}, x_{2 t-1}\right), p\left(x_{2 t}, x_{2 t+1}\right), \frac{1}{2}\left(p\left(x_{2 t-1}, x_{2 t}\right)+p\left(x_{2 t}, x_{2 t+1}\right)\right)\right\}\right) \\
& \leq \phi\left(\max \left\{p\left(x_{2 t}, x_{2 t-1}\right), p\left(x_{2 t}, x_{2 t+1}\right)\right\}\right) .
\end{aligned}
$$

If $\max \left\{p\left(x_{2 t}, x_{2 t-1}\right), p\left(x_{2 t}, x_{2 t+1}\right)\right\}=p\left(x_{2 t}, x_{2 t+1}\right)$, then (2.3) yields a contradiction. Thus, $\max \left\{p\left(x_{2 t}, x_{2 t-1}\right), p\left(x_{2 t}, x_{2 t+1}\right)\right\}=p\left(x_{2 t}, x_{2 t-1}\right)$ and hence

$$
p\left(x_{2 t}, x_{2 t+1}\right) \leq \phi\left(p\left(x_{2 t}, x_{2 t-1}\right)\right) .
$$

If $n$ is odd, then $n=2 t+1$ for some $t \in \mathbb{N} \cup\{0\}$. By similar arguments as above, we can show that

$$
p\left(x_{2 t+1}, x_{2 t+2}\right) \leq \phi\left(p\left(x_{2 t}, x_{2 t+1}\right)\right) .
$$

By (2.4) and (2.5), we have

$$
p\left(x_{n}, x_{n+1}\right) \leq \phi\left(p\left(x_{n-1}, x_{n}\right)\right)
$$

By repeating (2.6) $n$-times, we get $p\left(x_{n}, x_{n+1}\right) \leq \phi^{n}\left(p\left(x_{0}, x_{1}\right)\right)$. For $n, m \in \mathbb{N}$ with $m>n$, we have

$$
\begin{aligned}
p\left(x_{n}, x_{m}\right) & \leq \sum_{i=n}^{m-1} p\left(x_{i}, x_{i+1}\right)-\sum_{i=n}^{m-2} p\left(x_{i+1}, x_{i+1}\right) \leq \sum_{i=n}^{m-1} p\left(x_{i}, x_{i+1}\right) \\
& \leq \sum_{i=n}^{m-1} \phi^{i}\left(p\left(x_{0}, x_{1}\right)\right) \leq \sum_{i=n}^{\infty} \phi^{i}\left(p\left(x_{0}, x_{1}\right)\right) .
\end{aligned}
$$

Since $\phi$ is $(c)$-comparison, we have $\sum_{i=0}^{\infty} \phi^{i}\left(p\left(x_{0}, x_{1}\right)\right)$ converges and hence

$$
\lim _{n \rightarrow+\infty} \sum_{i=n}^{\infty} \phi^{i}\left(p\left(x_{0}, x_{1}\right)\right)=0 .
$$

So, $\lim _{n, m \rightarrow+\infty} p\left(x_{n}, x_{m}\right)=0$. Thus $\left(x_{n}\right)$ is a 0 -Cauchy sequence in $X$. Since $X$ is 0 -complete, there exists $z \in X$ such that $x_{n} \rightarrow z$ with $p(z, z)=0$. So,

$$
\lim _{n, m \rightarrow+\infty} p\left(x_{n}, x_{m}\right)=\lim _{n \rightarrow+\infty} p\left(x_{n}, z\right)=p(z, z)=0 .
$$

Now, we prove that $S z=z$ and $T z=z$. Since $p\left(x_{2 n+1}, z\right) \rightarrow p(z, z)=0$ and $p\left(x_{2 n+2}, z\right) \rightarrow$ $p(z, z)=0$, then by Lemma 1.2 we get

$$
\lim _{n \rightarrow+\infty} p\left(x_{2 n+1}, S z\right)=p(z, S z)
$$

and

$$
\lim _{n \rightarrow+\infty} p\left(x_{2 n+2}, T z\right)=p(z, T z) .
$$


By using (2.2), we have

$$
\begin{aligned}
p\left(x_{2 n+1}, S z\right)= & p\left(T x_{2 n}, S z\right) \\
\leq & \phi\left(\max \left\{p\left(x_{2 n}, z\right), p\left(x_{2 n}, T x_{2 n}\right), p(z, S z), \frac{1}{2}\left(p\left(T x_{2 n}, z\right)+p\left(x_{2 n}, S z\right)\right)\right\}\right) \\
& +L \min \left\{p^{w}\left(T x_{2 n}, z\right), p^{w}\left(x_{2 n}, S z\right)\right\} \\
= & \phi\left(\max \left\{p\left(x_{2 n}, z\right), p\left(x_{2 n}, x_{2 n+1}\right), p(z, S z), \frac{1}{2}\left(p\left(x_{2 n+1}, z\right)+p\left(x_{2 n}, S z\right)\right)\right\}\right) \\
& +L \min \left\{p^{w}\left(x_{2 n+1}, z\right), p^{w}\left(x_{2 n}, S z\right)\right\} .
\end{aligned}
$$

On letting $n \rightarrow+\infty$ in the above inequality and using (2.7) and (2.8), we get that $p(z, S z) \leq$ $\phi(p(z, S z))$. Since $\phi(t)<t$ for all $t>0$, we conclude that $p(z, S z)=0$. By using $\left(\mathrm{p}_{1}\right)$ and $\left(\mathrm{p}_{2}\right)$ of the definition of partial metric spaces, we get that $S z=z$. By similar arguments as above, we may show that $T z=z$.

The common fixed point of $S$ and $T$ in Theorem 2.1 is unique if we replaced $\min \left\{p^{w}(x, S y), p^{w}(T x, y)\right\}$ by $\min \left\{p^{w}(x, T x), p^{w}(x, S y), p^{w}(T x, y)\right\}$ in $(2.2)$. So, we have the following result.

Theorem 2.2 Let $(X, p)$ be a 0-complete partial metric space and $T, S: X \rightarrow X$ be two mappings such that

$$
\begin{aligned}
p(T x, S y) \leq & \phi\left(\max \left\{p(x, y), p(x, T x), p(y, S y), \frac{1}{2}(p(T x, y)+p(x, S y))\right\}\right) \\
& +L \min \left\{p^{w}(x, T x), p^{w}(x, S y), p^{w}(T x, y)\right\}
\end{aligned}
$$

for all $x, y \in X$. If $\phi$ is a (c)-comparison function, then the common fixed point of $T$ and $S$ is unique.

Proof The existence of the common fixed point of $T$ and $S$ follows from Theorem 2.1. To prove the uniqueness of the common fixed point of $T$ and $S$, we let $u, v$ be two common fixed points of $T$ and $S$. Then $T u=S u=u$ and $T v=S v=v$. Now, we will show that $u=v$. By (2.10), we have

$$
\begin{aligned}
p(u, v)= & p(T u, S v) \\
\leq & \phi\left(\max \left\{p(u, v), p(u, T u), p(v, S v), \frac{1}{2}(p(T u, v)+p(v, T u))\right\}\right) \\
& +L \min \left\{p^{w}(u, T u), p^{w}(T u, v), p^{w}(v, T u)\right\} \\
= & \phi\left(\max \left\{p(u, v), p(u, u), p(v, v), \frac{1}{2}(p(u, v)+p(v, u))\right\}\right) \\
& +L \min \left\{p^{w}(u, u), p^{w}(u, v), p^{w}(v, u)\right\} \\
= & \phi(p(u, v)) .
\end{aligned}
$$

Since $\phi(t)<t$ for all $t>0$, we conclude that $p(u, v)=0$. By $\left(\mathrm{p}_{1}\right)$ and $\left(\mathrm{p}_{2}\right)$ of the definition of partial metric spaces, we get that $u=v$. 
Taking $T=S$ in Theorems 2.1 and 2.2, we have the following results.

Corollary 2.1 Let $(X, p)$ be a 0 -complete partial metric space and $T: X \rightarrow X$ be a mapping such that

$$
\begin{aligned}
p(T x, T y) \leq & \phi\left(\max \left\{p(x, y), p(x, T x), p(y, T y), \frac{1}{2}(p(T x, y)+p(x, T y))\right\}\right) \\
& +L \min \left\{p^{w}(x, T y), p^{w}(T x, y)\right\}
\end{aligned}
$$

for all $x, y \in X$. If $\phi$ is a (c)-comparison function, then $T$ has a fixed point.

Corollary 2.2 Let $(X, p)$ be a 0 -complete partial metric space and $T: X \rightarrow X$ be a mapping such that

$$
\begin{aligned}
p(T x, T y) \leq & \phi\left(\max \left\{p(x, y), p(x, T x), p(y, T y), \frac{1}{2}(p(T x, y)+p(x, T y))\right\}\right) \\
& +L \min \left\{p^{w}(x, T x), p^{w}(x, T y), p^{w}(T x, y)\right\}
\end{aligned}
$$

for all $x, y \in X$. If $\phi$ is a (c)-comparison function, then $T$ has a unique fixed point.

By the aid of Lemma 2.1 of Ref. [44], we have the following consequence results of Corollaries 2.1 and 2.2.

Corollary 2.3 Let $(X, p)$ be a partial metric space and $T, S: X \rightarrow X$ be two mappings such that

$$
\begin{aligned}
p(T x, T y) \leq & \phi\left(\max \left\{p(S x, S y), p(S x, T x), p(S y, T y), \frac{1}{2}(p(T x, S y)+p(S x, T y))\right\}\right) \\
& +L \min \left\{p^{w}(S x, T y), p^{w}(S y, T x)\right\}
\end{aligned}
$$

for all $x, y \in X$. Also, suppose that

(1) $T X \subseteq S X$.

(2) $S X$ is a 0-complete subspace of the partial metric space $X$.

If $\phi$ is a (c)-comparison function, then $T$ and $S$ have a coincidence point. Moreover, the point of coincidence of $T$ and $S$ is unique.

Corollary 2.4 Let $(X, p)$ be a partial metric space and $T, S: X \rightarrow X$ be two mappings such that

$$
\begin{aligned}
p(T x, T y) \leq & \phi\left(\max \left\{p(S x, S y), p(S x, T x), p(S y, T y), \frac{1}{2}(p(T x, S y)+p(S x, T y))\right\}\right) \\
& +L \min \left\{p^{w}(T x, S x), p^{w}(S x, T y), p^{w}(S y, T x)\right\}
\end{aligned}
$$

for all $x, y \in X$. Also, suppose that

(1) $T X \subseteq S X$.

(2) $S X$ is a 0-complete subspace of the partial metric space $X$. 
If $\phi$ is a (c)-comparison function, then the point of coincidence of $T$ and $S$ is unique; that is, if $T u=S u$ and $T v=S v$, then $T u=T v=S v=S u$.

By taking $\phi(t)=k t, k \in[0,1)$ in Corollaries 2.1 and 2.2, we have the following results.

Corollary 2.5 Let $(X, p)$ be a 0 -complete partial metric space and $T: X \rightarrow X$ be a mapping such that

$$
\begin{aligned}
p(T x, T y) \leq & k \max \left\{p(x, y), p(x, T x), p(y, T y), \frac{1}{2}(p(T x, y)+p(x, T y))\right\} \\
& +L \min \left\{p^{w}(x, T y), p^{w}(T x, y)\right\}
\end{aligned}
$$

for all $x, y \in X$. If $0 \leq k<1$, then $T$ has a fixed point.

Corollary 2.6 Let $(X, p)$ be a 0 -complete partial metric space and $T: X \rightarrow X$ be a mapping such that

$$
\begin{aligned}
p(T x, T y) \leq & k \max \left\{p(x, y), p(x, T x), p(y, T y), \frac{1}{2}(p(T x, y)+p(x, T y))\right\} \\
& +L \min \left\{p^{w}(x, T x), p^{w}(x, T y), p^{w}(T x, y)\right\}
\end{aligned}
$$

for all $x, y \in X$. If $k \in[0,1)$, then $T$ has a unique fixed point.

By the aid of Lemma 2.1 of Ref. [44], we have the following consequence results of Corollaries 2.5 and 2.6.

Corollary 2.7 Let $(X, p)$ be a partial metric space and $T, S: X \rightarrow X$ be two mappings such that

$$
\begin{aligned}
p(T x, T y) \leq & k \max \left\{p(S x, S y), p(S x, T x), p(S y, T y), \frac{1}{2}(p(T x, S y)+p(S x, T y))\right\} \\
& +L \min \left\{p^{w}(S x, T y), p^{w}(S y, T x)\right\}
\end{aligned}
$$

for all $x, y \in X$. Also, suppose that

(1) $T X \subseteq S X$.

(2) SX is a 0-complete subspace of the partial metric space X.

If $k \in[0,1)$, then $T$ and $S$ have a coincidence point.

Corollary 2.8 Let $(X, p)$ be a partial metric space and $T, S: X \rightarrow X$ be two mappings such that

$$
\begin{aligned}
p(T x, T y) \leq & \phi\left(\max \left\{p(S x, S y), p(S x, T x), p(S y, T y), \frac{1}{2}(p(T x, S y)+p(S x, T y))\right\}\right) \\
& +L \min \left\{p^{w}(T x, S x), p^{w}(S x, T y), p^{w}(S y, T x)\right\}
\end{aligned}
$$

for all $x, y \in X$. Also, suppose that

(1) $T X \subseteq S X$.

(2) $S X$ is a 0 -complete subspace of the partial metric space $X$. 
If $k \in[0,1)$, then the point of coincidence of $T$ and $S$ is unique; that is, if $T u=S u$ and $T v=S v$, then $T u=T v=S v=S u$.

The (c)-comparison function in Theorems 2.1 and 2.2 can be replaced by a comparison function if we formulated the contractive condition to a suitable form. For this instance, we have the following result.

Theorem 2.3 Let $(X, p)$ be a 0 -complete partial metric space and $T: X \rightarrow X$ be a mapping such that

$$
\begin{aligned}
p(T x, T y) \leq & \phi(\max \{p(x, y), p(x, T x), p(y, T y)\}) \\
& +L \min \left\{p^{w}(x, T x), p^{w}(x, T y), p^{w}(y, T x)\right\}
\end{aligned}
$$

for all $x, y \in X$. If $\phi$ is a comparison function, then $T$ has a unique fixed point.

Proof Choose $x_{0} \in X$. Put $x_{1}=T x_{0}$. Again, put $x_{2} \in X$ such that $x_{2}=T x_{1}$. Continuing the same process, we can construct a sequence $\left(x_{n}\right)$ in $X$ such that $x_{n+1}=T x_{n}$. If $p\left(x_{k}, x_{k+1}\right)=0$ for some $k \in \mathbb{N}$, then by the definition of partial metric spaces, we have $x_{k}=x_{k+1}=T x_{k}$, that is, $x_{k}$ is a fixed point of $T$. Thus, we assume that $p\left(x_{n}, x_{n+1}\right) \neq 0$ for all $n \in \mathbb{N}$. By (2.11), we have

$$
\begin{aligned}
p\left(x_{n}, x_{n+1}\right)= & p\left(T x_{n-1}, T x_{n}\right) \\
\leq & \phi\left(\max \left\{p\left(x_{n-1}, x_{n}\right), p\left(x_{n-1}, T x_{n-1}\right), p\left(x_{n}, T x_{n}\right)\right\}\right) \\
& +L \min \left\{p^{w}\left(x_{n-1}, T x_{n}\right), p^{w}\left(x_{n-1}, T x_{n}\right), p^{w}\left(x_{n}, T x_{n-1}\right)\right\} \\
= & \phi\left(\max \left\{p\left(x_{n-1}, x_{n}\right), p\left(x_{n}, x_{n+1}\right)\right\}\right)+L \min \left\{p^{w}\left(x_{n-1}, x_{n+1}\right), p^{w}\left(x_{n}, x_{n}\right)\right\} \\
= & \phi\left(\max \left\{p\left(x_{n-1}, x_{n}\right), p\left(x_{n}, x_{n+1}\right)\right\}\right) .
\end{aligned}
$$

If

$$
\max \left\{p\left(x_{n-1}, x_{n}\right), p\left(x_{n}, x_{n+1}\right)\right\}=p\left(x_{n}, x_{n+1}\right),
$$

then

$$
p\left(x_{n}, x_{n+1}\right) \leq \phi\left(p\left(x_{n}, x_{n+1}\right)\right)<p\left(x_{n}, x_{n+1}\right)
$$

a contradiction. Thus,

$$
\max \left\{p\left(x_{n-1}, x_{n}\right), p\left(x_{n}, x_{n+1}\right)\right\}=p\left(x_{n-1}, x_{n}\right)
$$

and hence

$$
p\left(x_{n}, x_{n+1}\right) \leq \phi\left(p\left(x_{n-1}, x_{n}\right)\right) \quad \forall n \in \mathbb{N} .
$$

Repeating (2.12) $n$ times, we get that

$$
p\left(x_{n}, x_{n+1}\right) \leq \phi^{n}\left(p\left(x_{0}, x_{1}\right)\right) .
$$


Now, we will prove that $\left(x_{n}\right)$ is a Cauchy sequence in the partial metric space $(X, p)$. For this, given $\epsilon>0$, since $\frac{1}{2+L}(\epsilon-\phi(\epsilon))>0$ and $\lim _{n \rightarrow+\infty} \phi^{n}\left(p\left(x_{0}, x_{1}\right)\right)=0$, there exists $k \in \mathbb{N}$ such that $p\left(x_{n}, x_{n+1}\right)<\frac{1}{2+L}(\epsilon-\phi(\epsilon))$ for all $n \geq k$. Now, given $m, n \in \mathbb{N}$ with $m>n$. Claim: $p\left(x_{n}, x_{m}\right)<\epsilon$ for all $m>n \geq k$. We prove our claim by induction on $m$. Since $k+1>k$, then

$$
p\left(x_{k}, x_{k+1}\right)<\frac{1}{2+L}(\epsilon-\phi(\epsilon))<\epsilon \text {. }
$$

The last inequality proves our claim for $m=k+1$. Assume that our claim holds for $m=k$. To prove our claim for $m=k+1$, we have

$$
\begin{aligned}
p\left(x_{n}, x_{k+1}\right) & \leq p\left(x_{n}, x_{n+1}\right)+p\left(x_{n+1}, x_{k+1}\right)-p\left(x_{n+1}, x_{n+1}\right) \\
& \leq p\left(x_{n}, x_{n+1}\right)+p\left(x_{n+1}, x_{k+1}\right) \\
& =p\left(x_{n}, x_{n+1}\right)+p\left(T x_{n}, T x_{k}\right) .
\end{aligned}
$$

By (2.11), we have

$$
\begin{aligned}
p\left(T x_{n}, T x_{k}\right) \leq & \phi\left(\max \left\{p\left(x_{n}, x_{k}\right), p\left(x_{n}, T x_{n}\right), p\left(x_{k}, T x_{k}\right)\right\}\right) \\
& +L \min \left\{p\left(x_{n}, T x_{n}\right), p\left(x_{n}, T x_{k}\right), p\left(x_{k}, T x_{n}\right)\right\} \\
= & \phi\left(\max \left\{p\left(x_{n}, x_{k}\right), p\left(x_{n}, x_{n+1}\right), p\left(x_{k}, x_{k+1}\right)\right\}\right) \\
& +L \min \left\{p\left(x_{n}, x_{n+1}\right), p\left(x_{n}, x_{k+1}\right), p\left(x_{k}, x_{n+1}\right)\right\} \\
\leq & \phi\left(\operatorname { m a x } \left\{p\left(x_{n}, x_{k}\right), p\left(x_{n}, x_{n+1}\right), p\left(x_{k}, x_{k+1}\right)+L p\left(x_{n}, x_{n+1}\right) .\right.\right.
\end{aligned}
$$

If $\max \left\{p\left(x_{n}, x_{k}\right), p\left(x_{n}, x_{n+1}\right), p\left(x_{k}, x_{k+1}\right)\right\}=p\left(x_{n}, x_{k}\right)$, then by (2.13) we have

$$
\begin{aligned}
p\left(x_{n}, x_{k+1}\right) & \leq p\left(x_{n}, x_{n+1}\right)+\phi\left(p\left(x_{n}, x_{k}\right)\right)+L p\left(x_{n}, x_{n+1}\right) \\
& <\frac{1+L}{2+L}(\epsilon-\phi(\epsilon))+\phi(\epsilon) \\
& <\epsilon .
\end{aligned}
$$

If $\max \left\{p\left(x_{n}, x_{k}\right), p\left(x_{n}, x_{n+1}\right), p\left(x_{k}, x_{k+1}\right)\right\}=p\left(x_{n}, x_{n+1}\right)$, then by (2.13) we have

$$
\begin{aligned}
p\left(x_{n}, x_{k+1}\right) & \leq p\left(x_{n}, x_{n+1}\right)+\phi\left(p\left(x_{n}, x_{n+1}\right)\right)+L p\left(x_{n}, x_{n+1}\right) \\
& <(2+L) p\left(x_{n}, x_{n+1}\right) \\
& <\epsilon-\phi(\epsilon) \\
& <\epsilon .
\end{aligned}
$$

If $\max \left\{p\left(x_{n}, x_{k}\right), p\left(x_{n}, x_{n+1}\right), p\left(x_{k}, x_{k+1}\right)\right\}=p\left(x_{k}, x_{k+1}\right)$, then by (2.13) we have

$$
\begin{aligned}
p\left(x_{n}, x_{k+1}\right) & \leq p\left(x_{n}, x_{n+1}\right)+\phi\left(p\left(x_{k}, x_{k+1}\right)\right)+L p\left(x_{n}, x_{n+1}\right) \\
& <(1+L) p\left(x_{n}, x_{n+1}\right)+p\left(x_{k}, x_{k+1}\right)
\end{aligned}
$$




$$
\begin{aligned}
& <\frac{1+L}{2+L}(\epsilon-\phi(\epsilon))+\frac{1}{2+L}(\epsilon-\phi(\epsilon)) \\
& <\epsilon .
\end{aligned}
$$

Thus $\left(x_{n}\right)$ is a 0 -Cauchy sequence in $X$. Since $X$ is 0 -complete, then $\left(x_{n}\right)$ converges, with respect to $\tau_{p}$, to a point $z$ for some $z \in X$ such that

$$
\lim _{n, m \rightarrow+\infty} p\left(x_{n}, x_{m}\right)=\lim _{n \rightarrow+\infty} p\left(x_{n}, z\right)=p(z, z)=0
$$

Now, assume that $p(z, T z)>0$. By using $\left(\mathrm{p}_{4}\right)$ of the definition of partial metric spaces and (2.11), we have

$$
\begin{aligned}
p(z, T z) \leq & p\left(z, x_{n+1}\right)+p\left(x_{n+1}, T z\right) \\
= & p\left(z, x_{n+1}\right)+p\left(T x_{n}, T z\right) \\
\leq & p\left(z, x_{n+1}\right)+\phi\left(\max \left\{p\left(x_{n}, z\right), p\left(x_{n}, T x_{n}\right), p(z, T z)\right\}\right) \\
& +L \min \left\{p^{w}\left(x_{n}, T x_{n}\right), p^{w}\left(x_{n}, T z\right), p^{w}\left(T x_{n}, z\right)\right\} \\
= & p\left(z, x_{n+1}\right)+\phi\left(\max \left\{p\left(x_{n}, z\right), p\left(x_{n}, x_{n+1}\right), p(z, T z)\right\}\right) \\
& +L \min \left\{p^{w}\left(x_{n}, x_{n+1}\right), p^{w}\left(x_{n}, T z\right), p^{w}\left(x_{n+1}, S z\right)\right\} .
\end{aligned}
$$

Since

$$
\lim _{n, m \rightarrow+\infty} p\left(x_{n}, x_{n+1}\right)=\lim _{n \rightarrow+\infty} p\left(x_{n}, z\right)=0
$$

and $p(z, T z)>0$, we can choose $n_{0} \in \mathbb{N}$ such that

$$
\max \left\{p\left(x_{n}, z\right), p\left(x_{n}, x_{n+1}\right), p(z, T z)\right\}=p(z, T z)
$$

for all $n \geq n_{0}$. Thus (2.15) becomes

$$
p(z, T z) \leq p\left(z, x_{n+1}\right)+\phi(p(z, T z))+L \min \left\{p^{w}\left(x_{n}, x_{n+1}\right), p^{w}\left(x_{n}, T z\right), p^{w}\left(x_{n+1}, z\right)\right\},
$$

for all $n \geq n_{0}$. On letting $n \rightarrow+\infty$ in the above inequality and using 2.14, we get that $p(z, T z) \leq \phi(p(z, T z))<p(z, T z)$, a contradiction. Thus $p(z, T z)=0$. By using $\left(\mathrm{p}_{1}\right)$ and $\left(\mathrm{p}_{2}\right)$ of the definition of a partial metric space, we get that $z=T z$; that is, $z$ is a fixed point of $T$. To prove that the fixed point of $T$ is unique, we assume that $u$ and $v$ are fixed points of $T$. Thus, we have $T u=u$ and $T v=v$. By (2.11), we have

$$
\begin{aligned}
p(u, v)= & p(T u, T v) \\
\leq & \phi(\max \{p(u, v), p(u, T u), p(v, T v)\}) \\
& +L \min \{p(u, T u), p(u, T v), p(v, T u)\} \\
= & \phi(p(u, v)) .
\end{aligned}
$$

Since $\phi(t)<t$ for all $t \in \mathbb{N}$, we have $p(u, v)=0$. By $\left(\mathrm{p}_{1}\right)$ and $\left(\mathrm{p}_{2}\right)$, we have $u=v$. 
By the aid of Lemma 2.1 of Ref. [44], we have the following consequence result of Theorem 2.3.

Corollary 2.9 Let $(X, p)$ be a partial metric space and $T, S: X \rightarrow X$ be two mappings such that for some $L \geq 0$, we have

$$
\begin{aligned}
p(T x, T y) \leq & \phi(\max \{p(S x, S y), p(S x, T x), p(S y, T y)\}) \\
& +L \min \left\{p^{w}(S x, T x), p^{w}(S x, T y), p^{w}(S y, T x)\right\}
\end{aligned}
$$

for all $x, y \in X$. Also, suppose that

(1) $T X \subseteq S X$.

(2) $S X$ is a 0-complete subspace of the partial metric space $X$.

If $\phi$ is a comparison function, then $T$ and $S$ have a coincidence point. Moreover, the point of coincidence of $T$ and $S$ is unique.

The uniqueness of a common fixed point of $T$ and $S$ in Theorem 2.1 can be proved under an additional contractive condition based on a comparison function $\phi_{1}$.

Corollary 2.10 Let $(X, p)$ be a 0-complete partial metric space and $T, S: X \rightarrow X$ be two mappings. Assume there exists a (c)-comparison function $\phi$ such that the pair $(T, S)$ is a generalized $(\phi, L)$-weak contraction. Also, suppose that there exist a comparison function $\phi_{1}$ and $L_{1} \geq 0$ such that

$$
\begin{aligned}
p(T x, S y) \leq & \phi_{1}\left(\max \left\{p(x, y), p(x, T x), p(y, S y), \frac{1}{2}(p(T x, y)+p(x, S y))\right\}\right) \\
& +L p(x, T x)
\end{aligned}
$$

for all $x, y \in X$. Then $T$ and $S$ have a unique common fixed point.

Proof The existence of the common fixed point of $T$ and $S$ follows from Theorem 2.1. To prove the uniqueness of the fixed point, we assume that $u$ and $v$ are two fixed points of $T$ and $S$. Then by (2.16), we have

$$
\begin{aligned}
p(u, v) & =p(T u, S v) \\
& \leq \phi_{1}\left(\max \left\{p(u, v), p(u, T u), p(v, S v), \frac{1}{2}(p(T u, v)+p(u, S v))\right\}\right)+L_{1} p(u, T u) \\
& =\phi_{1}(p(u, v)) .
\end{aligned}
$$

Since $\phi_{1}(t)<t$ for all $t>0$, we get $p(u, v)=0$ and hence $u=v$.

Taking $S=T$ in Corollary 2.10, we have the following result.

Corollary 2.11 Let $(X, p)$ be a 0 -complete partial metric space and $T: X \rightarrow X$ be a mapping. Assume there exists a (c)-comparison function $\phi$ such that

$$
p(T x, T y) \leq \phi\left(\max \left\{p(x, y), p(x, T x), p(y, T y), \frac{1}{2}(p(T x, y)+p(x, T y))\right\}\right)+L p(x, T x)
$$


for all $x, y \in X$. Also, suppose that there exist a comparison function $\phi_{1}$ and $L_{1} \geq 0$ such that

$$
\begin{aligned}
p(T x, S y) \leq & \phi_{1}\left(\max \left\{p(x, y), p(x, T x), p(y, S y), \frac{1}{2}(p(T x, y)+p(x, S y))\right\}\right) \\
& +L p(x, T x)
\end{aligned}
$$

for all $x, y \in X$. Then $T$ has a unique fixed point.

By the aid of Lemma 2.1 of [44], we have the following result.

Corollary 2.12 Let $(X, p)$ be a partial metric space and $T, S: X \rightarrow X$ be two mappings. Suppose there exist a (c)-comparison function $\phi$ and $L \geq 0$ such that

$$
\begin{aligned}
p(T x, T y) \leq & \phi\left(\max \left\{p(S x, S y), p(S x, T x), p(S y, T y), \frac{1}{2}(p(T x, S y)+p(S x, T y))\right\}\right) \\
& +L \min \left\{p^{w}(S x, T y), p^{w}(S y, T x)\right\}
\end{aligned}
$$

for all $x, y \in X$. Also, assume that there exist a comparison function $\phi_{1}$ and $L_{1} \geq 0$ such that

$$
\begin{aligned}
p(T x, T y) \leq & \phi\left(\max \left\{p(S x, S y), p(S x, T x), p(S y, T y), \frac{1}{2}(p(T x, S y)+p(S x, T y))\right\}\right) \\
& +L p(S x, T x)
\end{aligned}
$$

for all $x, y \in X$. Moreover, assume that

(1) $T X \subseteq S X$.

(2) $S X$ is a 0 -complete subspace of the partial metric space $X$.

Then the point of coincidence of $T$ and $S$ is unique.

Now, we introduce an example satisfying the hypotheses of Theorem 2.3 to support the useability of our results.

Example 2.1 Let $X=[0,1]$. Define a partial metric $p: X \times X \rightarrow[0,+\infty)$ by the formula $p(x, y)=\max \{x, y\}$. Also, define $T: X \rightarrow X$ by $T x=\frac{x}{1+x}$ and the comparison function $\phi:[0,+\infty) \rightarrow[0,+\infty)$ by $\phi(t)=\frac{t}{1+t}$. Then, we have

(1) $(X, p)$ is a 0 -complete partial metric space.

(2) For any $L \geq 0$, the inequality

$$
p(T x, T y) \leq \phi(\max \{p(x, y), p(x, T x), p(y, T y)\})+L \min \left\{p^{w}(x, T x), p^{w}(x, T y), p^{w}(y, T x)\right\}
$$

holds for all $x, y \in X$.

(3) There are no (c)-comparison function $\phi$ and $L \geq 0$ such that the inequality

$$
p(T x, T y) \leq \phi(p(x, y))+L \min \left\{p^{w}(x, T y), p^{w}(y, T x)\right\}
$$

holds for all $x, y \in X$. 
Proof To prove (2), given $x, y \in X$. Without loss of generality, we may assume that $y \leq x$.

Thus, we have

$$
\begin{aligned}
p(T x, T y) & =p\left(\frac{x}{1+x}, \frac{y}{1+y}\right) \\
& =\frac{x}{1+x} \\
& =\phi(x) \\
& \leq \phi(\max \{p(x, y), p(x, T x), p(y, T y)\})+L \min \left\{p^{w}(x, T x), p^{w}(x, T y), p^{w}(y, T x)\right\} .
\end{aligned}
$$

To prove (3), we assume that there exist a (c)-comparison function $\phi$ and some $L \geq 0$ such that

$$
p(T x, T y) \leq \phi(p(x, y))+L \min \left\{p^{w}(x, T y), p^{w}(y, T x)\right\}
$$

holds for all $x, y \in X$.

Thus,

$$
p\left(T \frac{1}{n}, T \frac{1}{n+1}\right) \leq \phi\left(p\left(\frac{1}{n}, \frac{1}{1+n}\right)\right)+L \min \left\{p^{w}\left(\frac{1}{n}, T \frac{1}{n+1}\right), p^{w}\left(\frac{1}{n+1}, T \frac{1}{n}\right)\right\}
$$

holds for all $n \in \mathbb{N}$. Hence

$$
p\left(\frac{1}{n+1}, \frac{1}{n+2}\right) \leq \phi\left(p\left(\frac{1}{n}, \frac{1}{1+n}\right)\right)+L \min \left\{p^{w}\left(\frac{1}{n}, \frac{1}{n+2}\right), p^{w}\left(\frac{1}{n+1}, \frac{1}{n+1}\right)\right\}
$$

holds for all $n \in \mathbb{N}$. Therefore, for $n \in \mathbb{N}$, we have

$$
\frac{1}{1+n} \leq \phi\left(\frac{1}{n}\right)
$$

By induction on $n$, we can show that

$$
\frac{1}{1+n} \leq \phi^{n}(1)
$$

holds for all $n \in \mathbb{N}$. Since $\sum_{n=0}^{\infty} \frac{1}{1+n}$ diverges, we have $\sum_{n=0}^{\infty} \phi^{n}(1)$ diverges. So, $\phi$ is not a (c)-comparison function.

Remark Example 2.1 satisfies the hypotheses of Theorem 2.3 and does not satisfy the hypotheses of Theorem 3 and Theorem 4 of [43].

\section{Remarks}

(1) Theorem 1.1 [43, Theorem 3] is a special case of Corollary 2.1.

(2) $[43$, Corollary 1$]$ is a special case of Corollary 2.5.

(3) Theorem 1.2 [43, Theorem 4] is a special case of Corollary 2.10. 


\section{Conclusion}

In this paper, we introduced the notion of a generalized $(\phi, L)$-weak contraction. In the first part of this paper, we utilized our definition to derive a common fixed point of two self-mappings $T$ and $S$ under a (c)-comparison function $\phi$. Also, we used Lemma 2.1 of Ref. [44] to derive a common fixed point of two self-mappings $T$ and $S$. In the second part of this paper, we generalized the main result (Theorem 3 ) of [43] by proving Theorem 2.3 under a comparison function. Also, we utilized Lemma 2.1 of Ref. [44] to derive a common coincidence point of two self-mappings $T$ and $S$. Finally, we closed our paper by introducing Example 2.1 which satisfies the hypotheses of our result Theorem 2.3 and does not satisfy the hypotheses of Theorems 3,4 of [43].

Competing interests

The authors declare that they have no competing interests.

\section{Authors' contributions}

Both authors contributed equally and significantly in writing this article. Both authors read and approved the final manuscript.

\section{Author details}

${ }^{1}$ Department of Mathematics, Hashemite University, Zarqa, Jordan. ${ }^{2}$ Faculty of Applied Sciences, University Politehnica of Bucharest, 313 Splaiul Independenţei, Bucharest, 060042, Romania.

\section{Acknowledgements}

The authors would like to thank the editor and the referees for their useful comments and remarks.

Received: 15 November 2012 Accepted: 21 February 2013 Published: 12 March 2013

\section{References}

1. Matthews, SG: Partial metric topology. In: Papers on General Topology and Applications (Flushing, NY, 1992). Ann. New York Acad. Sci., vol. 728, pp. 183-197 (1994)

2. Abdeljawad, T, Karapinar, E, Taş, K: Existence and uniqueness of a common fixed point on partial metric spaces. Appl. Math. Lett. 24(11), 1900-1904 (2011)

3. Abdeljawad, T, Karapinar, E, Taş, K: A generalized contraction principle with control functions on partial metric spaces. Comput. Math. Appl. 63(3), 716-719 (2012)

4. Abdeljawad, T: Fixed points for generalized weakly contractive mappings in partial metric spaces. Math. Comput. Model. 54(11-12), 2923-2927 (2011)

5. Altun, I, Erduran, A: Fixed point theorems for monotone mappings on partial metric spaces. Fixed Point Theory Appl. 2011, Article ID 508730 (2011)

6. Altun, I, Simsek, H: Some fixed point theorems on dualistic partial metric spaces. J. Adv. Math. Stud. 1(1-2), 1-8 (2008)

7. Altun, I, Simsek, H: Some fixed point theorems on ordered metric spaces and application. Fixed Point Theory Appl. 2010, Article ID 6214469 (2010)

8. Altun, I, Sola, F, Simsek, H: Generalized contractions on partial metric spaces. Topol. Appl. 157(18), 2778-2785 (2010)

9. Altun, I, Sadarangani, K: Corrigendum to 'Generalized contractions on partial metric spaces' [Topology Appl. 157 (2010) 2778-2785]. Topol. Appl. 158(13), 1738-1740 (2011)

10. Aydi, H: Some fixed point results in ordered partial metric spaces. J. Nonlinear Sci. Appl. 4(2), 1-12 (2011)

11. Aydi, H: Some coupled fixed point results on partial metric spaces. Int. J. Math. Math. Sci. 2011, Article ID 647091 (2011)

12. Aydi, H: Fixed point theorems for generalized weakly contractive condition in ordered partial metric spaces. J. Nonlinear Anal. Optim. 2(2), 33-48 (2011)

13. Aydi, H, Karapinar, E, Shatanawi, W: Coupled fixed point results for $(\psi, \varphi)$-weakly contractive condition in ordered partial metric spaces. Comput. Math. Appl. 62, 4449-4460 (2011)

14. Ćirić, L, Samet, B, Aydi, H, Vetro, C: Common fixed points of generalized contractions on partial metric spaces and an application. Appl. Math. Comput. 218, 2398-2406 (2011)

15. Golubović, Z, Kadelburg, Z, Radenović, S: Coupled coincidence points of mappings in ordered partial metric spaces. Abstr. Appl. Anal. 2012, Article ID 192581 (2012)

16. Karapınar, E, Erhan, I: Fixed point theorems for operators on partial metric spaces. Appl. Math. Lett. 24, 1894-1899 (2011)

17. Nashine, HK, Kadelburg, Z, Radenović, S: Common fixed point theorems for weakly isotone increasing mappings in ordered partial metric spaces. Math. Comput. Model. (2011). doi:10.10016/j.mcm.2011.12.019

18. Oltra, S, Valero, O: Banach's fixed point theorem for partial metric spaces. Rend. Ist. Mat. Univ. Trieste 36(1-2), 17-26 (2004)

19. Romaguera, S: A Kirk type characterization of completeness for partial metric spaces. Fixed Point Theory Appl. 2010 Article ID 493298 (2010)

20. Romaguera, S: Fixed point theorems for generalized contractions on partial metric spaces. Topol. Appl. 159, 194-199 (2012) 
21. Samet, B, Rajović, M, Lazović, R, Stoiljković, R: Common fixed point results for nonlinear contractions in ordered partial metric spaces. Fixed Point Theory Appl. 2011, Article ID 71 (2011)

22. Shatanawi, W, Nashine, HK: A generalization of Banach's contraction principle for nonlinear contraction in a partial metric space. J. Nonlinear Sci. Appl. 5, 37-43 (2012)

23. Shatanawi, W, Nashine, HK, Tahat, N: Generalization of some coupled fixed point results on partial metric spaces. Int. J. Math. Math. Sci. 2012, Article ID 686801 (2012)

24. Shatanawi, W, Samet, B, Abbas, M: Coupled fixed point theorems for mixed monotone mappings in ordered partial metric spaces. Math. Comput. Model. 55, 680-687 (2012)

25. Berinde, V: Approximating fixed points of weak $\phi$-contractions using the Picard iteration. Fixed Point Theory Appl. 4(2), 131-142 (2003)

26. Berinde, V: Approximating fixed points of weak contractions using the Picard iteration. Nonlinear Anal. Forum 9(1), 43-53 (2004)

27. Berinde, $V$ : On the approximation of fixed points of weak contractive mappings. Carpath. J. Math. 19(1), 7-22 (2003)

28. Berinde, V: General constructive fixed point theorems for Ćirić-type almost contractions in metric spaces. Carpath. J. Math. 24(2), 10-19 (2008)

29. Berinde, V: Approximating common fixed points of noncommuting discontinuous weakly contractive mappings in metric spaces. Carpath. J. Math. 25(1), 13-22 (2009)

30. Berinde, V: Some remarks on a fixed point theorem for Ćirić-type almost contractions. Carpath. J. Math. 25(2), 157-162 (2009)

31. Berinde, V: Approximating common fixed points of noncommuting almost contractions in metric spaces. Fixed Point Theory Appl. 11(2), 179-188 (2010)

32. Berinde, $\mathrm{V}$ : Common fixed points of noncommuting almost contractions in cone metric spaces. Math. Commun. 15(1), 229-241 (2010)

33. Babu, GVR, Sandhya, ML, Kameswari, MVR: A note on a fixed point theorem of Berinde on weak contractions. Carpath. J. Math. 24(1), 8-12 (2008)

34. Păcurar, M: Sequences of almost contractions and fixed points. Carpath. J. Math. 24(2), 101-109 (2008)

35. Păcurar, M: Iterative Methods for Fixed Point Approximation. Editura Risoprint, Cluj-Napoca (2009)

36. Pǎcurar, M: Remark regarding two classes of almost contractions with unique fixed point. Creat. Math. Inform. 19(2), 178-183 (2010)

37. Păcurar, M: Fixed point theory for cyclic Berinde operators. Fixed Point Theory Appl. 12(2), 419-428 (2011)

38. Samet, B, Vetro, C: Berinde mappings in orbitally complete metric space. Chaos Solitons Fractals 44(12), 1075-1079 (2011)

39. Sintunavarat, W, Kumam, P: Weak condition for generalized multi-valued $(f, \alpha, \beta)$-weak contraction mappings. Appl. Math. Lett. 24(4), 460-465 (2011)

40. Shatanawi, W: Some fixed point results for a generalized $\psi$-weak contraction mappings in orbitally metric spaces. Chaos Solitons Fractals 45, 520-526 (2012)

41. Shatanawi, W, Al-Rawashdeh, A: Common fixed points of almost generalized $(\psi, \phi)$-contractive mappings in ordered metric spaces. Fixed Point Theory Appl. 2012, Article ID 80 (2012)

42. Suzuki, T: Fixed point theorems for Berinde mappings. Bull. Kyushu Inst. Technol., Pure Appl. Math. 58, 13-19 (2011)

43. Altun, I, Acar, Ö: Fixed point theorems for weak contractions in the sense of Berinde on partial metric spaces. Topol. Appl. 159, 2642-2648 (2012)

44. Haghi, RH, Rezapour, S, Shahzad, N: Some fixed point generalizations are not real generalizations. Nonlinear Anal. 74, 1799-1803 (2011)

\section{Submit your manuscript to a SpringerOpen ${ }^{\circ}$ journal and benefit from:}

- Convenient online submission

Rigorous peer review

- Immediate publication on acceptance

- Open access: articles freely available online

- High visibility within the field

- Retaining the copyright to your article 